\title{
Proposal for New Classification and Practical Use of Diuretics According to Their Effects on the Serum Chloride Concentration: Rationale Based on the "Chloride Theory"
}

Hajime Kataoka

Received: April 7, 2020 / Published online: May 6, 2020

(C) The Author(s) 2020

\section{ABSTRACT}

Currently, diuretic therapy for heart failure (HF) pathophysiology is primarily focused on the sodium and water balance. Over the last several years, however, chloride $(\mathrm{Cl})$ has been recognized to have an important role in HF pathophysiology, as both a prognostic marker and a possible central factor regulating the body fluid status. I recently proposed a unifying hypothesis for HF pathophysiology, called the "chloride theory", during HF worsening and recovery, as follows. Chloride is the key electrolyte for regulating both reabsorption of tubular electrolytes and water in the kidney through the renin-angiotensin-aldosterone system and distributing body fluid in each compartment of the body. As changes between the serum $\mathrm{Cl}$ concentration and plasma volume are intimately associated with worsening $\mathrm{HF}$ and its recovery after decongestive therapy, modulation of the serum $\mathrm{Cl}$ concentration by careful selection and combination of various diuretics and their doses could become an attractive therapeutic option for HF. In this review, I will propose a new classification and practical use of diuretics according to their effects on the serum $\mathrm{Cl}$ concentration. Diuretic use according to this classification is expected to be a useful strategy for the treatment of patients with HF.

Keywords: Acetazolamide; Chloride; Diuretics; Heart failure; Loop diuretic; SGLT2 inhibitor; Vasopressin receptor antagonist

Digital features To view digital features for this article go to https://doi.org/10.6084/m9.figshare.12162012.

H. Kataoka $(\bowtie)$

Internal Medicine, Nishida Hospital, Oita, Japan

e-mail: hkata@cream.plala.or.jp 


\section{Key Summary Points}

According to the "chloride theory" for heart failure (HF) pathophysiology, modulation of the serum chloride $(\mathrm{Cl})$ concentration by careful selection and combination of various diuretics and their doses could become an attractive therapeutic option for HF

This review article initially describes possible physiologic roles and differential effects of $\mathrm{Cl}$ in comparison with sodium, the recently developed concept of the "chloride theory", and a diuretic strategy for HF pathophysiology according to this theory

Then, new classifications and the appropriate use of diuretics according to their effects on the serum $\mathrm{Cl}$

concentration, aiming to achieve an ideal body fluid status and avoid diuretic resistance, will be described

Lastly, a practical monitoring method and adjustment of diuretics in patients with HF, with respect to the "chloride theory", will be described to provide suitable $\mathrm{Cl}$ centered diuretic strategies

Further studies are required to determine the clinical utility of chloride-centered diuretic strategies compared with loop diuretic-centered diuretic strategies by recruiting both a large number and wide spectrum of patients with $\mathrm{HF}$

\section{INTRODUCTION}

Body fluid overload is a hallmark feature of unstable heart failure (HF) $[1,2]$. In the chronic HF population, plasma volume is reported to be contracted in many [3-6], but not all $[7,8]$ previous studies. Importantly, hypervolemia is often unrecognized in chronic HF [9], and

might be associated with HF hospitalization or worse clinical outcomes $[5,6,8,9]$.

Acute HF represents a broad spectrum of disease states, with heterogeneous clinical presentations, but is commonly characterized by either a rapid onset or a progressive worsening of signs and symptoms, requiring immediate treatment and leading to urgent hospitalization [10]. The initial clinical presentation of acute HF includes several distinct phenotypes such as acutely decompensated HF, cardiogenic shock, pulmonary edema, right-sided $\mathrm{HF}$, hypertensive $\mathrm{HF}$, and $\mathrm{HF}$ in the setting of acute coronary syndrome [11]. Worsening HF episodes sometimes occur because of body fluid redistribution with minimal body weight gain [12-14], but the vast majority of acute HF episodes are characterized by worsening symptoms and signs of congestion due to fluid volume overload $[10,15]$.

The initiation of fluid retention in various HF states primarily originates from cardiac pump failure itself, and subsequent cardiorenal interactions induce body fluid retention due to impaired renal sodium and water excretion secondary to neurohumoral upregulation [16]. Given the centrality of congestion to both the symptoms and outcomes of HF, diuretics remain the cornerstone for management of HF pathophysiology $[17,18]$, including maintaining stable HF or treating acutely worsening HF. Currently, diuretic therapy for HF pathophysiology is focused primarily on the handling of sodium and water. In the last several years, however, chloride $(\mathrm{Cl})$ has been recognized to have an important role in HF pathophysiology, as both a prognostic marker $[19,20]$ and a possible factor for the regulation of body fluid [21].

In this paper, I initially describe possible physiologic roles and differential effects of $\mathrm{Cl}$ in comparison with sodium, the recently developed concept of the "chloride theory", and a diuretic strategy for HF pathophysiology according to this theory [21]. New classifications and the appropriate use of diuretics according to their effects on the serum $\mathrm{Cl}$ concentration, aiming to achieve an ideal body fluid status and avoid diuretic resistance, will then be described. Lastly, a practical monitoring 
method and adjustment of diuretics in patients with HF, with respect to the "chloride theory", will be described to provide suitable Cl-centered diuretic strategies. This article is based on previously conducted studies and does not contain any studies with human participants or animals performed by any of the authors.

\section{CENTRAL ROLE OF CHLORIDE AND PROPOSAL OF THE "CHLORIDE THEORY" FOR HF PATHOPHYSIOLOGY}

In HF pathophysiology, body fluid volume regulation is a complex process involving the interaction of various afferent (sensory) and neurohumoral efferent (effector) mechanisms $[2,22,23]$. Historically, most studies have focused on the body fluid dynamics in HF through controlling the sodium and water balance in the body [24-26], and maintaining arterial circulatory integrity through the neurohumoral system is central to the unifying hypothesis of body fluid regulation in $\mathrm{HF}$ pathophysiology $[2,22,23]$. The pathophysiologic background of the biochemical determinants of vascular volume in HF, however, is not yet clarified. Recent studies demonstrated that changes in vascular [27-29] and red blood cell [30] volumes are independently associated with the serum $\mathrm{Cl}$ concentration, but not the serum sodium concentration, during worsening $\mathrm{HF}$ and its recovery. These observations led me to develop a unifying hypothesis for HF pathophysiology named the "chloride theory" during worsening HF (Fig. 1) and its recovery (Fig. 2) $[21,31]$, as follows. Chloride is the key electrolyte for regulating the reabsorption of both tubular electrolytes and water in the kidney through the renin-angiotensin-aldosterone system (RAAS) and regulating the body fluid distribution in each compartment of the body $[32,33]$, i.e., the intravascular, interstitial, and intracellular compartments.

\section{IMPORTANCE OF BIOCHEMICAL DIFFERENCES BETWEEN SODIUM AND CHLORIDE FOR BODY FLUID DISTRIBUTION}

Regulation of the body fluid volume is critically important for maintaining life. Body composition is approximately $60 \%$ water by weight, two-thirds of which (40\% water by weight) comprises the intracellular water compartment with the remaining one-third $(20 \%$ water by weight) comprising the extracellular water space. The extracellular water space is further subdivided into the intravascular compartment (arterial, capillary, venous, and lymphatic) and the interstitial compartment (5\% and 15\% water by weight, respectively) [32, 33]. The association between the electrolyte balance and fluid distribution in the human body is an important consideration, particularly the contribution of $\mathrm{Cl}$ ions for regulating the distribution of water in the human body.

Solutes in the human body are classified as effective or ineffective osmoles on the basis of their ability to generate osmotic water movement, and osmotic water flux requires a solute concentration gradient [33]. "Tonicity" is the effective osmolality across a barrier and hence regulates the distribution of free water to each body space compartment. As mentioned above, $\mathrm{Cl}$ ions, not sodium ions, should be the key electrolytes for regulating the plasma volume under HF status in the human body [27, 29]. Thus, compared with cationic sodium ions, anionic $\mathrm{Cl}$ ions in the human body create potential "tonicity" in the vascular space, making $\mathrm{Cl}$ ions the key electrolytes for regulating the distribution of water that can freely move across the vascular, interstitial, and cellular spaces. Sodium is not distributed in the body solely as a free cation, but it is also bound to large interstitial glycosaminoglycan networks in different tissues, which have an important regulatory function for the serum sodium content $[34,35]$. The interactions among cationic sodium ions, anionic $\mathrm{Cl}$ ions, and water, and their distribution under various HF states should be investigated in detail in future studies. 


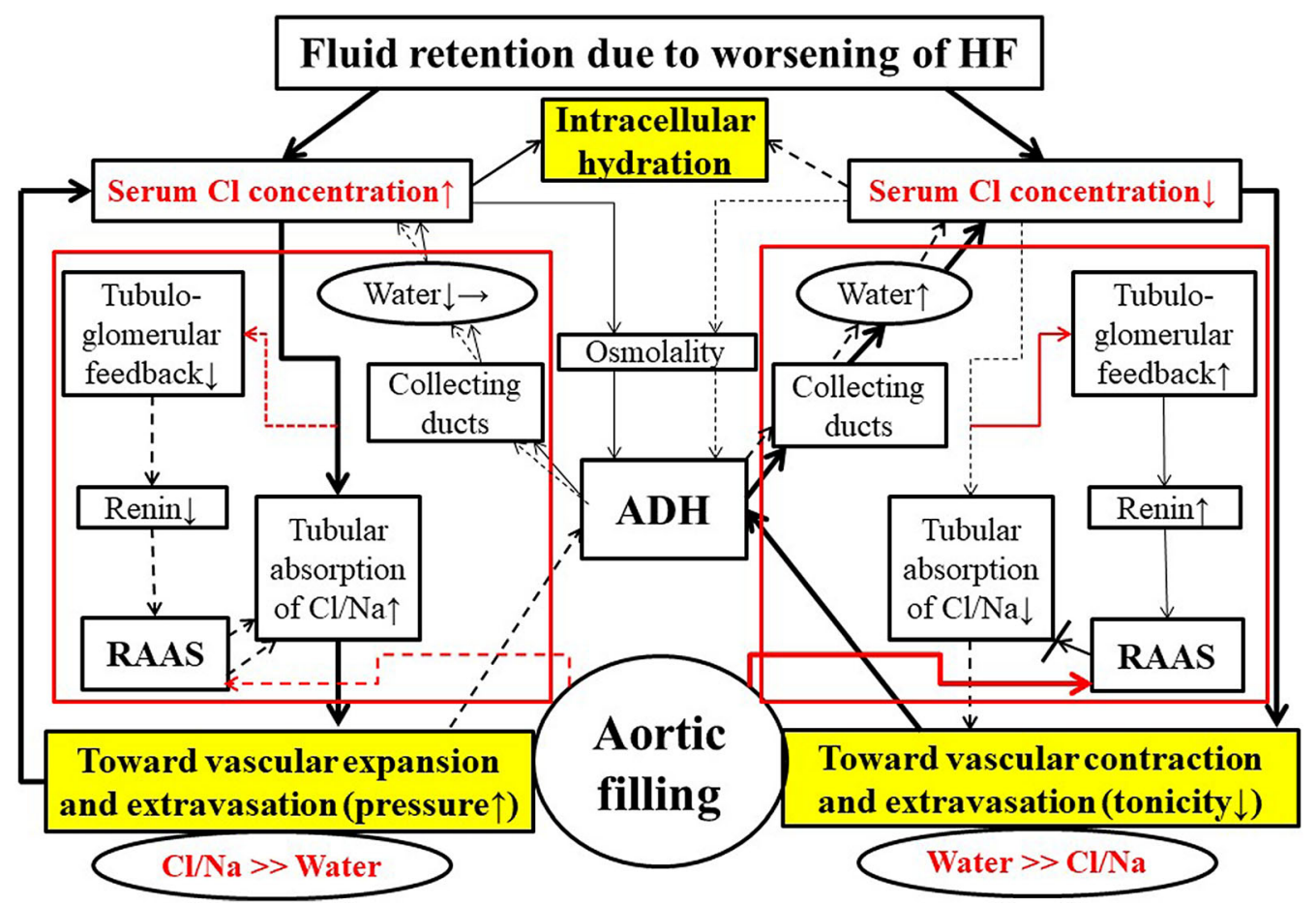

Fig. 1 Hypothesis of the "chloride theory" underlying worsening HF. Solid line indicates enhanced supply or excitatory effect and dotted line indicates reduced supply or inhibitory effect. Different effect strengths are expressed

The recent concept of the "revised Starling equation and the glycocalyx model" of transvascular fluid exchange states that the endothelial glycocalyx layer is semipermeable with respect to anionic macromolecules such as albumin and other plasma proteins, and generates an effective oncotic gradient within a very small space [36]. This theory, however, does not take into account the anionic $\mathrm{Cl}$ ions in the mechanisms of fluid movement across the vascular and interstitial spaces under worsening HF or its resolution. Additional studies are required to determine whether or not the endothelial glycocalyx layer regulates the movement of anionic $\mathrm{Cl}$ ions and, if so, how such a mechanism induces the movement of cationic sodium ions and water under an as yet unknown biochemical regulatory system for transvascular fluid exchange. by the thickness of each line. $\mathrm{ADH}$ antidiuretic hormone, $\mathrm{Cl}$ chloride, $\mathrm{HF}$ heart failure, $\mathrm{Na}$ sodium, RAAS renin-angiotensin-aldosterone system

\section{HF-RELATED DYSCHLOREMIA AND DIURETIC STRATEGY ACCORDING TO THE "CHLORIDE THEORY"}

Physiologically, fluid overload generally results in vascular expansion and tissue edema. Impaired oxygen and metabolic diffusion, distorted tissue architecture, obstruction of capillary blood flow and lymphatic drainage, and disturbed cell-cell interactions due to tissue edema may then contribute to progressive organ dysfunction $[37,38]$. The ideal cascade of decongestion by diuretic therapy for patients with HF is continuous removal of the extravasated fluid at the interstitial and third spaces [39-41] by the venous and lymphatic systems, which is pumped out from the body via the cardiorenal system, and eventual regain of individualized intravascular euvolemic status [42] to retain adequate arterial and ventricular 


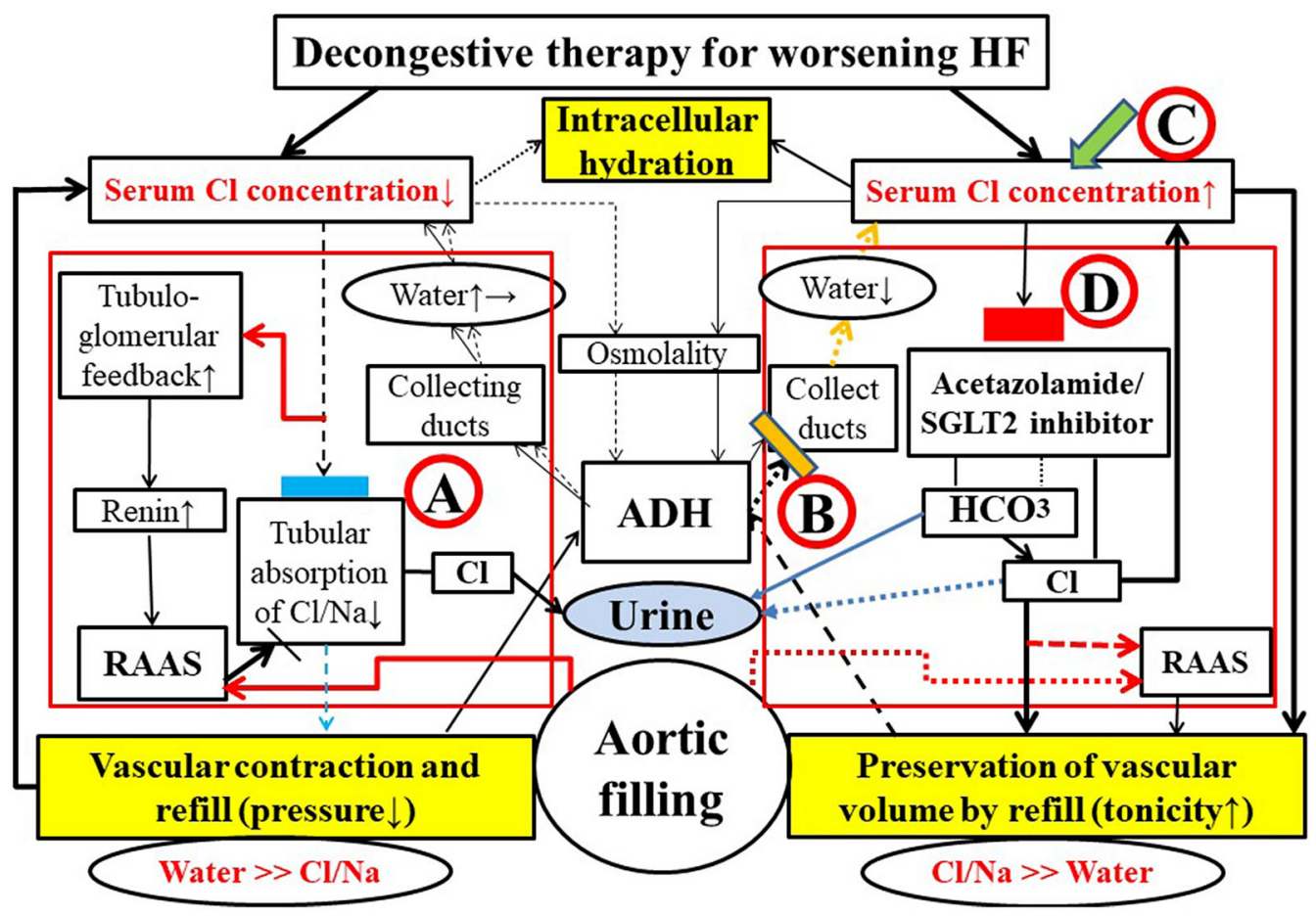

Fig. 2 Hypothesis of the "chloride theory" underlying the therapeutic resolution of worsening HF; conventional diuretic therapy (circled A), $\mathrm{V}_{2}$-receptor antagonist (circled B), $\mathrm{Cl}$ supplementation (circled C), and acetazolamide (carbonic anhydrase inhibitor) or SGLT2i (circled D). Blue and yellow blocks represent inhibition of the absorption of $\mathrm{Cl} / \mathrm{Na}$ and water in each. Red block indicates the inhibitory action of carbonic anhydrase inhibitor or SGLT2i. Therapeutic effect induced by each

filling in relation to compromised cardiac function, and to relieve venous congestion [29].

Diuretic treatment for various HF states, however, is often accompanied by troublesome serum electrolyte disturbances. The mechanisms responsible for electrolyte disturbances in cardiovascular patients may be multifactorial and interrelated, resulting from neurohormonal activation, renal dysfunction, medications (including various diuretics), and dietary intake [43]. Diuretic strategies adhering closely to the usage of loop and thiazide/thiazide-type diuretics could potentially be the most important factor contributing to the development of an electrolyte imbalance in patients with HF $[17,18]$. Classical and newly developed diuretics, e.g., acetazolamide, amiloride, and treatment is shown by a solid or dotted line. Solid line indicates enhanced supply or excitatory effect and dotted line indicates reduced supply or inhibitory effect. Different effect strengths are expressed by the thickness of each line. $\mathrm{ADH}$ antidiuretic hormone, $\mathrm{Cl}$ chloride, $\mathrm{HCO}_{3}{ }^{-}$bicarbonate, HF heart failure, $\mathrm{Na}$ sodium, RAAS renin-angiotensin-aldosterone system, SGLT2i sodium-glucose cotransporter 2 inhibitor

sodium-glucose cotransporter 2 inhibitor (SGLT2i), have been used sporadically to obtain more diuresis clinically, particularly in diureticresistant patients with HF [18], but not with the intent of modifying electrolyte disturbances. When focusing on correcting abnormalities in the serum $\mathrm{Cl}$ concentration according to the "chloride theory" (Figs. 1, 2), the optimal usage of classical and newly developed diuretics would effectively modify the serum $\mathrm{Cl}$ concentration, which could subsequently improve the body fluid dysregulation and diuretic efficiency in $\mathrm{HF}$, as described below.

The serum electrolyte concentration in a given body fluid state is determined by the relative balance between the total quantities of electrolytes and the amount of water in the 


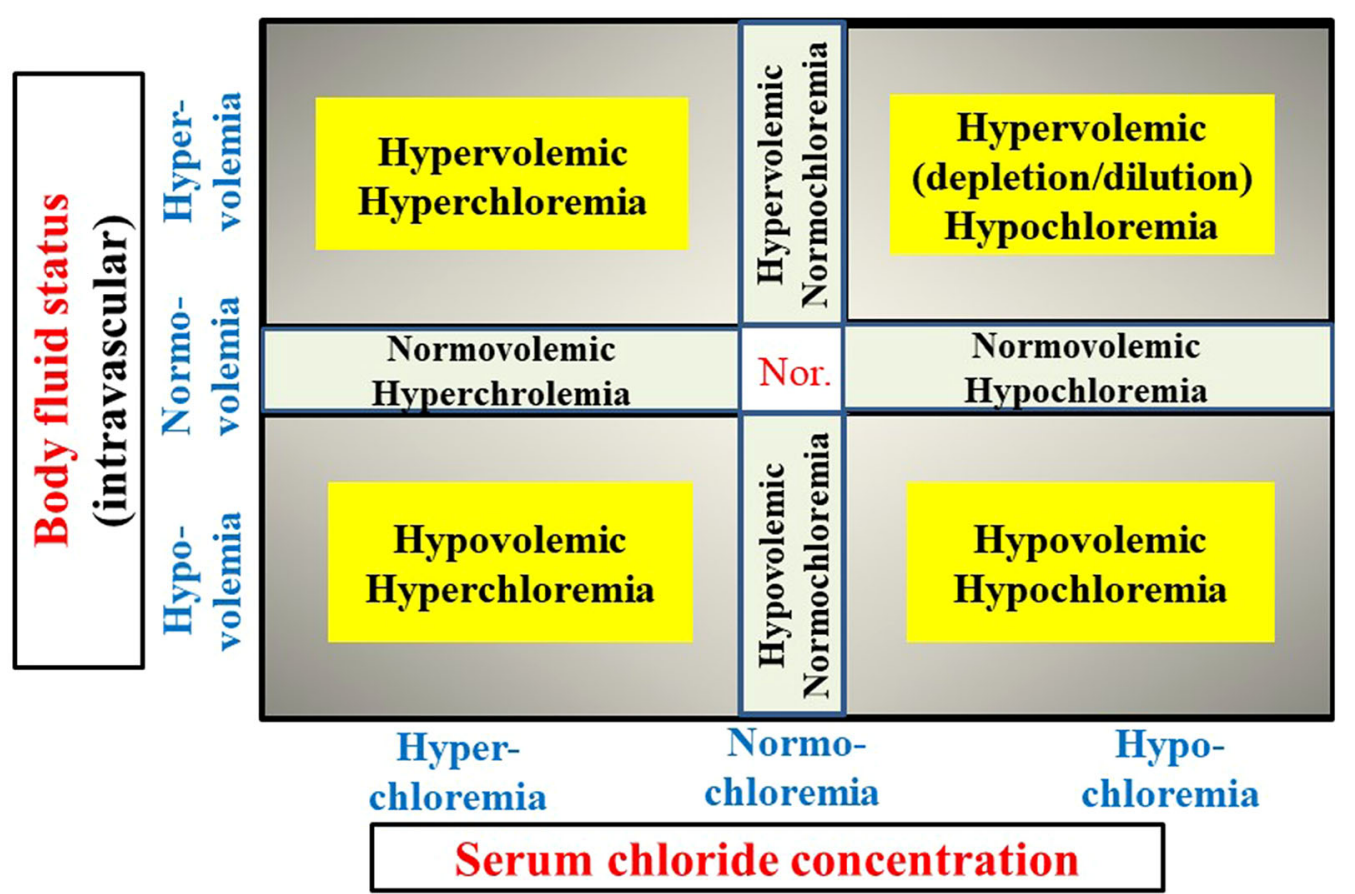

Fig. 3 Nine subsets of dyschloremia, including normal status (Nor.), stratified by amount of fluid volume (i.e., hyper-, normo-, and hypovolemia) and quantity of serum chloride in the vascular space (i.e., hyper-, normo-, and hypochloremia)

vascular space. Accordingly, dyschloremia under HF pathophysiology can be categorized into nine subsets based on the body fluid status (hyper-/normo-/hypovolemia) and the serum $\mathrm{Cl}$ concentration status (hyper-/normo-/hypochloremia), as shown in Fig. 3. Importantly, hypervolemic hypochloremia includes two distinct types of abnormalities, i.e., "depletion" vs "dilution", similar to the classification of hyponatremia in acute decompensated HF [44]. Because changes in the serum $\mathrm{Cl}$ concentration and plasma volume during $\mathrm{HF}$ worsening (Fig. 1) [27, 28] are intimately associated with recovery of HF worsening after decongestive therapy (Fig. 2) [29], modulation of these subsets of dyschloremia (Fig. 3) by the appropriate selection of diuretic selection and their doses, and combinations of various diuretics as described below, could become an attractive therapeutic option for cardiovascular patients. Modulation of the serum $\mathrm{Cl}$ concentration is usually accompanied by the same directional changes in the serum sodium concentration because the changes in their serum concentrations are correlated [45]. Of course, coexistent and marked serum sodium abnormalities should be corrected separately by selecting the appropriate diuretic and/or dietary modification $[43,44]$.

An understanding of the "chloride theory" of worsening HF pathophysiology (Fig. 1) $[21,28,31]$ can guide valuable and rational pharmacologic decongestion therapy as presented in Fig. 2, such as reducing the serum $\mathrm{Cl}$ concentration by using conventional diuretics for HF worsening with a higher concentration or quantity of serum $\mathrm{Cl}$ [45-48] (Fig. 2, circled A); and preserving and enhancing the serum $\mathrm{Cl}$ concentration with aquaresis using a vasopressin receptor antagonists [48-51] (Fig. 2, circled B); and supplementing $\mathrm{Cl}$ (Fig. 2, circled C) by hyperosmotic saline infusion $[52,53]$ or by "lysine chloride", which was reported in a recent study [20] of worsening HF with a lower serum $\mathrm{Cl}$ concentration. Diuretic treatment using the carbonic anhydrase inhibitor acetazolamide [31, 54-59] (Fig. 2, circled D) could become an attractive therapy for patients with HF and hypochloremia owing to its effects to 
improve the accompanying electrolyte disturbances.

The new glucose-lowering SGLT2i drugs are reported to exert diuresis through osmotic and natriuretic effects that contribute to plasma contraction, decrease blood pressure, and possibly prevent occurrence of HF events in patients with $[60,61]$ and without diabetes mellitus [62]. Findings from recent experimental $[63,64]$ and clinical [65] studies indicate that SGLT2i preserves or enhances the serum $\mathrm{Cl}$ concentration in patients without HF but with type 2 diabetes mellitus, potentially through aquaresis, aldosterone activation, and serum $\mathrm{HCO}_{3}{ }^{-}$concentration-decreasing effects [65]. Such a chloride-regaining diuretic effect of an SGLT2i would preserve plasma volume and renal function, and drain interstitial body fluid by the serum $\mathrm{Cl}$-associated enhancement of vascular "tonicity" (Fig. 2, D) [21, 29, 65]. This concept is consistent with recent clinical observations that SGLT2i reduces interstitial congestion without deleterious effects of arterial underfilling and predominantly decreases extravascular fluid retention [66].

\section{PROPOSAL FOR NEW DIURETIC CLASSIFICATION

AND ACHIEVEMENT OF OPTIMAL
DECONGESTION ACCORDING
TO THE "CHLORIDE THEORY"

According to the above discussion, it is reasonable to classify diuretics on the basis of their effects on the serum $\mathrm{Cl}$ concentration, as summarized in Table 1. The current classification and crude pharmacologic properties of diuretics will need to be revised and modified according to their effects on the serum $\mathrm{Cl}$ concentration to provide a more encompassing clinical description based on real-world pharmacologic studies. Achievement of an individualized optimal plasma volume and resolution of congestion are two main purposes of diuretic therapy for controlling HF. Unrecognized hypervolemia or a higher than ideal plasma volume, despite diuretic treatment to control HF, is deeply associated with a higher risk of an HF-related adverse outcome $[5,6,8,9]$, possibly related to a greater cardiac burden due to elevated cardiac filling pressures, impaired renal function due to elevated renal venous and abdominal pressures [67-69], and other organ injuries or damage associated with congestion [37, 38]. Thus, modulation of the plasma volume, which could easily be estimated by changes in the peripheral hemoglobin or hematocrit level [70-72], might be an attractive target for tailored patient care [8]. In the setting of acute HF, achievement of an appropriate hemoconcentration with decongestion treatment is associated with a reduced risk of mortality, even with the induction of worsening of renal function [70-72].

The hemoconcentration after decongestion treatment for acute HF, however, might weakly relate to the improvement of clinical congestion signs, and persistent congestion after treatment would be associated with increased mortality regardless of the hemoconcentration [73]. Persistent signs of congestion under aggressive diuretic treatment for patients with HF [74] should be managed irrespective of the induction of the hemoconcentration [73] or appearance of worsening renal function [75].

Because changes in the plasma volume are strongly associated with the serum $\mathrm{Cl}$ concentration [27-29] (Figs. 1, 2), modulation of the serum $\mathrm{Cl}$ concentration and its quantity through the proper selection, combination, and amount of diuretic(s) according to the new diuretic classification (Table 1) would allow for rational decision-making to achieve the ideal plasma volume and resolve congestive signs in parallel with maintaining a harmonic electrolyte balance. In general, the use of loop and thiazide diuretics can efficiently reduce the plasma volume by depleting serum $\mathrm{Cl}$ (left half of Fig. 2), but induction of hypochloremia by these diuretics may induce resistance to these diuretics [20]. Removing the extravasated fluid from the interstitial and third spaces [39-41] is also important toward reducing organ damage $[37,38]$, and this process could be effectively accomplished by enhancing the serum $\mathrm{Cl}$ concentration [21] with the use of Cl-regaining diuretics, such as acetazolamide, vasopressin receptor antagonists, and SGLT2i (right half of Fig. 2). 
Table 1 Classification of diuretic agents according to their effects on the serum chloride concentration $[45,48-51,54-56,58,59,64,65]$

\begin{tabular}{|c|c|c|c|c|c|c|c|c|}
\hline \multirow[t]{2}{*}{ Diuretic agent } & \multirow[t]{2}{*}{ Main mechanism } & \multicolumn{4}{|c|}{ Urinary excretion } & \multicolumn{3}{|c|}{$\begin{array}{l}\text { Serum } \\
\text { concentration }\end{array}$} \\
\hline & & $\overline{\mathrm{Cl}}$ & $\mathrm{Na}$ & $\mathbf{K}$ & Other & $\overline{\mathrm{Cl}}$ & $\mathrm{Na}$ & $\mathbf{K}$ \\
\hline \multicolumn{9}{|c|}{ A. To decrease serum $\mathrm{Cl}$ concentration } \\
\hline $\begin{array}{l}\text { 1. Loop } \\
\text { diuretics }\end{array}$ & $\begin{array}{l}\text { Blocks sodium-potassium-chloride cotransporter in } \\
\text { thick ascending limb of the loop of Henle }\end{array}$ & $\uparrow$ & $\uparrow$ & $\uparrow$ & & $\downarrow$ & $\downarrow$ & $\downarrow$ \\
\hline $\begin{array}{l}\text { 2. Thiazide } \\
\text { diuretics }\end{array}$ & $\begin{array}{l}\text { Blocks sodium-chloride cotransporter in the distal } \\
\text { convoluted tubule }\end{array}$ & $\uparrow$ & $\uparrow$ & $\uparrow$ & & $\downarrow$ & $\downarrow$ & $\downarrow$ \\
\hline \multicolumn{9}{|c|}{ B. To enhance serum $\mathrm{Cl}$ concentration } \\
\hline $\begin{array}{l}1 . \\
\text { Acetazolamide }\end{array}$ & Blocks carbonic anhydrase in the proximal tubule & $\downarrow$ & $\uparrow$ & $\uparrow$ & $\begin{array}{l}\mathrm{HCO}_{3} \uparrow ; \\
\quad \text { Water } \uparrow\end{array}$ & $\uparrow$ & $\uparrow \rightarrow$ & $\downarrow$ \\
\hline $\begin{array}{l}\text { 2. Aquaretic } \\
\text { diuretics }\end{array}$ & $\begin{array}{l}\text { Blocks vasopressin } V_{2} \text { receptor in the collecting duct of } \\
\text { the distal tubule }\end{array}$ & $\rightarrow$ & $\rightarrow$ & $\rightarrow$ & Water $\uparrow \uparrow$ & $\uparrow$ & $\uparrow$ & $\uparrow$ \\
\hline $\begin{array}{l}\text { 3. SGLT2 } \\
\text { inhibitor }\end{array}$ & Blocks SGLT2 in the proximal tubule & $\downarrow$ & $\uparrow \rightarrow$ & $\rightarrow$ & $\begin{array}{r}\text { Glucose } \uparrow ; \\
\text { Water } \uparrow\end{array}$ & $\uparrow$ & $\uparrow \rightarrow$ & $\rightarrow$ \\
\hline \multicolumn{9}{|c|}{ C. To have a neutral effect on serum $\mathrm{Cl}$ concentration } \\
\hline 1. MRA & $\begin{array}{l}\text { Antagonizes aldosterone receptor in the collecting duct } \\
\text { of the distal tubule }\end{array}$ & $?$ & $\uparrow$ & $\downarrow$ & $\begin{array}{l}\mathrm{H} \uparrow ; \\
\quad \mathrm{HCO}_{3} \uparrow\end{array}$ & $\rightarrow$ & $\downarrow$ & $\uparrow$ \\
\hline
\end{tabular}

$C l$ chloride, $K$ potassium, $M R A$ mineralocorticoid-receptor antagonists, $N a$ sodium, $S G L T 2$ sodium-glucose cotransporter 2

Diuretic therapy to increase or supply $\mathrm{Cl}$ in the plasma may lead to residual cardiac volume overload in relation to individual cardiac function, possibly ensuring a persistent burden on the heart. Indeed, my recent study [54] demonstrated that, while both acetazolamide (chloride retention) and loop/thiazide diuretics (chloride depletion) achieved the same body weight reduction by diuresis, the plasma volume and renal function were preserved under acetazolamide treatment, but the magnitude of the serum b-type natriuretic peptide (BNP) reduction induced by treatment with acetazolamide was small compared to that induced by loop/thiazide diuretics. The serum BNP level is not adequately reduced by the use of vasopressin antagonists [50] and SGLT2i $[76,77]$ as diuretics. The "chloride theory" provides a possible mechanism for the inadequate BNP reduction by these diuretics. Namely, administration of these Cl-regaining diuretics efficiently removes interstitial fluid, but preserves vascular volume, which results in residual burden on a patient's heart after therapy with a vasopressin receptor antagonist [78, 79] or SGLT2i [76, 77]. When the cardiac burden persists even under adequate diuretic therapy for unloading the heart, strategies to further reduce the cardiac burden or enhance cardiac power are required in parallel, such as by using inotropes, controlling blood pressure and heart rate, modulating cardiac re-synchronization, and ultrafiltration $[47,80]$. Appropriate use of vasodilators or blockade of the RAAS to increase venous capacitance may be an important therapeutic option for reducing the cardiac burden $[13,14]$. 


\section{INAPPROPRIATE USE OF CONVENTIONAL DIURETICS AND INDUCTION OF DIURETIC RESISTANCE}

Severity of cardiac and/or renal dysfunction substantially contributes to the diuretic efficacy in worsening $\mathrm{HF}$ as some studies report that lower blood pressure and high blood urea nitrogen are associated with a poor diuretic response [81, 82]. Though loop diuretics may not extend survival in patients with chronic HF, they are currently the foundation of life-saving therapy during acutely decompensated HF and maintaining euvolemia [46, 47, 80]. Diuretic resistance during treatment of patients with HF has many causes $[83,84]$, but a diuretic-associated cause is highly problematic because adequate diuresis to achieve euvolemia is the primary purpose of the treatment for worsening HF. Loop diuretic-associated resistance develops with repeated administration of loop diuretics due to (1) activation of the RAAS; (2) activation of the sympathetic nervous system, which reduces renal blood flow and the quantities of sodium and of the diuretic reaching the loop of Henle; and (3) hypertrophy of the epithelial cells in the distal nephron, causing increased sodium reabsorption $[17,83]$. As a consequence, fluid overload may persist or recur despite higher diuretic doses. Such persistent congestion is associated with a poor clinical outcome $[5,8,74,75]$, and must be managed as quickly as possible. One approach to overcome loop diuretic resistance is the addition of a thiazidetype diuretic to produce diuretic synergy via sequential nephron blockade $[46,83]$. Sequential nephron blockade may be accompanied by inappropriate fluid loss, electrolyte imbalance (hyponatremia or hypokalemia), and worsening renal function [46, 80, 83]. If residual congestion persists or progressively worsens despite higher doses of conventional diuretics, adherence to such decongestive therapy may promote a vicious cycle of HF worsening and RAAS activation [85-88], leading to worsening HF with a decreased serum $\mathrm{Cl}$ concentration as shown in the right half of Fig. 1; such a patient with worsening $\mathrm{HF}$ might present with progressive hypochloremia, extravasated fluid retention, intravascular volume contraction, hypotension, and worsening renal function.

It should be noted that, besides advanced cardiac and renal dysfunction [89], an important cause of diuretic resistance may be the inappropriate use of conventional diuretics for different HF states with various serum electrolyte abnormalities. Therefore, loop diuretics or combinations of thiazide/thiazide-like diuretics at higher doses are not the best treatment option for worsening HF with progressive hypochloremia or hyponatremia. Indeed, the appearance of hypochloremia is strongly related to diuretic resistance under HF treatment [20]. In such a situation, the decongestion strategy should be changed on the basis of a comprehensive mechanistic understanding of the role of $\mathrm{Cl}$ in $\mathrm{HF}$ pathophysiology [21,31]. The use of "chloride-regaining" diuretics, along with hyperosmotic saline infusion, as shown in right half of Fig. 2 and Table 1, may improve hypochloremia-associated diuretic resistance [20], and such a diuretic approach for modulating the serum $\mathrm{Cl}$ concentration under the appropriate circumstances would be worth trying.

\section{MONITORING HF STATUS AND ADJUSTING DIURETICS UNDER THE "CHLORIDE THEORY"}

During follow-up of patients with HF undergoing decongestion therapy, adequate monitoring of symptoms, signs, and suitable clinical tests for evaluating $\mathrm{HF}$ status [18, 38, 90-98] are required to correctly identify stability or worsening of $\mathrm{HF}$, and to subsequently decide whether or not to reconstruct the appropriate diuretic treatment [99] to achieve an individualized optimal plasma volume and freedom from decongestive signs and symptoms.

Table 2 shows many clinical tests, arbitrarily classified into specified categories, that allow for point-of-care evaluation of each component that comprises various HF presentations. The selection and combination of clinical tests shown in Table 2 must be individualized by clinicians according to the possible utility. Dyspnea is the most common HF-related 
Table 2 Monitoring of symptoms, signs, and clinical tests for evaluation of compartments of heart failure presentation

Heart failure-associated symptoms; breathlessness (dyspnea), fatigue

Blood pressure

Heart rate

Oxygen saturation

Physical sign; peripheral cyanosis

Pulse oximetry

Blood gas analysis

Burden to the cardiac function

Physical sign; auscultatory third heart sound

B-type natriuretic peptide

Echocardiography with Doppler study; ventricular function, atrial size, pulmonary artery pressure

Gain and loss of body fluid

Body weight

Urine volume

Intravascular body fluid

Physical sings; neck vein distension, apical displacement, hepatomegaly

Hemoglobin, hematocrit, estimated plasma volume

Ultrasound; distended inferior vena cava with reduced respiratory collapse

Extravascular body fluid

Physical sings; systemic edema, pulmonary rales, hepatomegaly, ascites

Ultrasound; pulmonary B-lines, pleural effusion

Bio-impedance analysis

Intracellular volume status

Red blood cell volume

Bio-impedance analysis

Renal function

Blood urea nitrogen, serum creatinine, estimated glomerular filtration rate, uric acid
Table 2 continued

Serum electrolytes

Sodium, potassium, chloride, magnesium, uric acid

Others

Neurohormones; renin-angiotensin-aldosterone system, anti-diuretic hormone

Cardiac injury; cardiac enzymes, creatinine kinase, troponin

symptom. Thus, monitoring of dyspnea is clinically important, but patients often wait until their symptoms lead them to present to the emergent clinic [100, 101], particularly elderly patients who may have poor functional capacity, cognitive impairment, and comorbidity $[102,103]$. Consequently, monitoring of the HF status relies more on objective assessments and response to treatment than on symptoms. Among HF-related signs, elevated jugular venous pressure, third heart sound, and displacement of the apical impulse may be more specific, but they are more difficult to detect and have poor reproducibility $[90,95,104]$. In contrast, pulmonary crackles (rales) [105] and leg edema [106] frequently appear in patients without HF. These signs, despite being not specific and having limited value for correctly diagnosing HF status among the general population with a low prevalence of patients with $\mathrm{HF}$, may be useful for detecting worsening HF episodes during follow-up of patients with established HF because they are highly sensitive and leading HF signs that often appear among patients with established HF during follow-up [94].

The HF status of each patient can be categorized on the basis of clinician-estimated volume status (wet/dry) and perfusion status (warm/cold) [96]. This widespread simplified classification system for patients with HF might be useful to characterize the HF status at a glance, but it is not adequate to precisely evaluate a patient's HF status. Accordingly, several diagnostic steps can be applied as a practical monitoring method for identifying HF status, mainly incorporating simple items for 
estimating changes in the cardiac burden, body fluid intake and output, body fluid distribution, renal function, and electrolyte balance. That is, the main modalities for evaluating HF status include physical examination, blood tests (serum BNP level, peripheral blood, renal function, and electrolytes), and ultrasound. At first, the simplest and most reliable test for monitoring changes in the cardiac burden is the measurement of serial serum BNP peptides $[90,95,97,107,108]$ though there are wide intra-individual fluctuations in serum BNP levels over 1-2 months, even under a stable HF status $[109,110]$. Second, short-term changes in the body weight $[81,91,94,111]$ are also a reliable measure for evaluating a body fluid gain or loss because fluid is the body component with the ability to undergo the most rapid change, so a substantial change in body weight over a short period would relate most directly to the fluid status [112]. Monitoring urine volume, of course, is important for evaluating diuresis, but may have limited value because of the influence on urine volume by the amount of water intake [50]. Body weight gain and leg edema in isolation are non-specific, but the coexistence of these two signs efficiently supports HF worsening [94]. Third, assessment of changes in each compartment of the body $[32,33]$ is adequate. Physical examination is the principal step for this purpose, in which appearance of bilateral leg edema is the leading sign of worsening HF, followed by neck vein distention and pulmonary crackles [90, 94]. Searching for thoracic fluid congestion by ultrasound is strongly recommended to detect worsening HF, because a simple chest X-ray has limited ability for identifying pulmonary congestion or pleural effusion in patients with HF [113], but ultrasound detection of pulmonary congestion [97, 114] and pleural fluid $[92,94,115]$ is highly sensitive and specific for diagnosing HF worsening in patients with established HF. Ultrasound evaluation of the inferior vena cava and estimated pulmonary artery pressure $[18,97,98]$ would be suitable to evaluate the severity of the left- and right-sided circulatory burden or congestive status. Examples of monitoring patients with established HF according to these recommended items are described elsewhere [31, 50, 58, 116].

Clinical decisions regarding the HF status should be based on a comprehensive evaluation of all HF-related symptoms, signs, and clinical tests because a single clinical symptom, sign, or test may lack sensitivity or specificity. If the aforementioned clinical evaluation suggests a worsening HF status, the clinician must reconstruct a therapeutic strategy for HF treatment. The therapeutic approach for congestion depends on whether vascular-type fluid redistribution or cardiac-type fluid accumulation is the primary cause of the worsening HF [12-14]. Diuretics are guideline-recommended first-line therapy in patients with "wet and warm" HF [96] in whom congestion is predominantly attributable to fluid accumulation and volume overload. A diuretic approach to patients with acute or chronic HF should be initiated according to the standard guideline-based strategy [18, 38, 95]. Loop diuretics form the backbone of diuretic therapy in acute HF, and are used in over $90 \%$ of patients. Thus, a stepped pharmacologic approach should be applied using the mainstay of loop diuretics $[17,117]$ in combination with an appropriate thiazide or thiazide-like diuretic and/or mineralocorticoid receptor antagonists [18, 38, 95]. Measurement of the post-diuretic urinary sodium concentration [18] or its urinary excretion quantity [118] early after treatment may be useful for following loop diuretic efficacy. Diuretic treatment for HF is often accompanied by serum electrolyte disturbances already existing at the initial presentation and/or appearing during HF treatment. In such situations, understanding the "chloride theory" of worsening HF pathophysiology $[21,28,31]$ would provide valuable and rational pharmacologic decongestion strategies as mentioned in the previous sections, and as summarized in Figs. 1 and 2, and Table 1. It is important to assess serial changes in the vascular volume and serum $\mathrm{Cl}$ concentration, and their interactions, as shown in Figs. 1 and 2 . Measurement of the hemoglobin/hematocrit levels [70-72] or estimated plasma volume $[5,6,8,27]$ is suitable for assessing changes in the intravascular volume in parallel with determining diuretic efficacy by monitoring 
changes in the body weight to determine the amount of diuresis [81], serum BNP level for reducing the cardiac burden [107], and other clinical tests for evaluating each component of HF presentation (Table 2).

Diuretics are often ineffective in patients with congestion caused by vascular-type fluid redistribution, generally observed as increased congestion despite a lack of weight gain and predominantly indicated by hypertension [12-14]. Though both mechanisms, i.e., volume overload and volume redistribution, may contribute to congestion in many patients with worsening $\mathrm{HF}$, the clinician should differentiate between these two phenomena because the therapeutic strategy in the latter situation includes vasodilatory agents instead of diuretics [18, 38, 95]. Similarly, diuretics are deeply associated with changes in the RAAS activity $[119,120]$ via possible mechanisms through their effects on $\mathrm{Cl}$ dynamics and vascular volume, as predicted by the "chloride theory" [21]. Accordingly, RAAS blockers increase renal blood flow and decrease proximal tubular sodium reabsorption. Therefore, it is not surprising that they are among the first agents demonstrated to be effective in hypotonic dilutional hyponatremia, perhaps including dilutional hypochloremia, in patients with HF [44, 85-88]. RAAS blockades should always be titrated up in this case if there are no contraindications, such as coexisting renal dysfunction, hypotension, and HF with preserved ejection fraction $[17,44,121]$.

\section{CONCLUSIONS}

Optimal volume, traditionally termed "euvolemia", is an extremely vague definition and could suitably be redefined to represent a "good volume" that is associated with the best clinical outcomes in HF populations [42]. The "chloride theory" does not fully explain the complex HF pathophysiology, but in clinical practice at present, the "chloride theory" for HF pathophysiology (Figs. 1, 2) could provide a primary care and management system for diuretic treatment of patients with HF, with attention to the serum $\mathrm{Cl}$ concentration and changes central to this system. With regard to the status of the body fluid and serum $\mathrm{Cl}$ concentration under HF treatment (Fig. 3), HF-related evaluation (Table 2) would be adequate for proper selection of the diuretic type, and its use and dosage according to the new classification of diuretics (Table 1). The most important goal of diuretic therapy is to adequately reduce plasma volume to mitigate the cardiac burden and ameliorate organ congestion to improve their function through optimal diuresis, in parallel with preserving the renal function, maintaining the serum electrolyte balance, and avoiding excess diuresis and dehydration [122]. As differential body fluid status and background mechanisms may exist in obese vs non-obese patients with HF $[40,123,124]$, modification of diuretic strategies, including other pharmacologic therapies, might be required to treat patients with HF with reduced ejection fraction vs obese patients with HF with preserved ejection fraction [125-127]. Further studies are required to determine the clinical utility of chloride-centered diuretic strategies compared with loop diuretic-centered diuretic strategies [18, 38, 95] by recruiting both a large number and wide spectrum of patients with HF.

\section{ACKNOWLEDGEMENTS}

Funding. No funding or sponsorship was received for this study or for the journals rapid service publication fee.

Authorship. All named authors meet the International Committee of Medical Journal Editors (ICMJ) criteria for authorship for this article, take responsibility for the integrity of the work as a whole, and have given their approval for this version to be published.

Disclosures. Hajime Kataoka has nothing to disclose.

Compliance with Ethics Guidelines. This article is based on previously conducted studies and does not contain any studies with human 
participants or animals performed by the author.

Data Availability. Data sharing is not applicable to this article as no datasets were generated or analyzed during the current study.

Open Access. This article is licensed under a Creative Commons Attribution-NonCommercial 4.0 International License, which permits any non-commercial use, sharing, adaptation, distribution and reproduction in any medium or format, as long as you give appropriate credit to the original author(s) and the source, provide a link to the Creative Commons licence, and indicate if changes were made. The images or other third party material in this article are included in the article's Creative Commons licence, unless indicated otherwise in a credit line to the material. If material is not included in the article's Creative Commons licence and your intended use is not permitted by statutory regulation or exceeds the permitted use, you will need to obtain permission directly from the copyright holder. To view a copy of this licence, visit http://creativecommons.org/licenses/by$\mathrm{nc} / 4.0 /$.

\section{REFERENCES}

1. Anand IS, Ferrari R, Kalra GS, Wahi PL, Poole-Wilson PA, Harris PC. Edema of cardiac origin: studies of body water and sodium, renal function, hemodynamic indexes, and plasma hormones in untreated congestive cardiac failure. Circulation. 1989;80:299-305.

2. Kalra PR, Anagnostopoulos C, Bolger AP, Coats AJS, Anker SD. The regulation and measurement of plasma volume in heart failure. J Am Coll Cardiol. 2002;39:1901-8.

3. Feigenbaum MS, Welsch MA, Mitchell M, Vincent K, Braith RW, Pepine CJ. Contracted plasma and blood volume in chronic heart failure. J Am Coll Cardiol. 2000;35:51-5.

4. Bonfils PK, Damgaard M, Taskiran M, Goetze JP, Norsk P, Gadsboll N. Impact of diuretic treatment and sodium intake on plasma volume in patients with compensated systolic heart failure. Eur Heart J. 2010;12:995-1001.
5. Ling HZ, Flint J, Damgaard M, et al. Calculated plasma volume status and prognosis in chronic heart failure. Eur J Heart Fail. 2015;17:35-43.

6. Duarte K, Monnez JM, Albuisson E, Pitt B, Zannad F, Rossignol P. Prognostic value of estimated plasma volume in heart failure. J Am Coll Cardiol Heart Fail. 2015;3:886-93.

7. Adlbrecht C, Kommata S, Hulsmann M, et al. Chronic heart failure lead to an expanded plasma volume and pseudoanaemia, but does not lead to a reduction in the body's red cell volume. Eur Heart J. 2008;29:2343-50.

8. Martens P, Nijst P, Dupont M, Mullens W. The optimal plasma volume status in heart failure in relation to clinical outcome. J Card Fail. 2019;25: 240-8.

9. Androne AS, Hryniewicz K, Hudaihed A, Mancini D, Lamanca J, Katz SD. Relation of unrecognized hypervolemia in chronic heart failure to clinical status, hemodynamics, and patient outcomes. Am J Cardiol. 2004;93:1254-9.

10. Chioncel O, Mebazaa A, Harjola VP, et al. Clinical phenotypes and outcome of patients hospitalized for acute heart failure: the ESC heart failure longterm registry. Eur J Heart Fail. 2017;19:1242-54.

11. Dickstein K, Cohen-Solal A, Filippatos G, et al. Guidelines for the diagnosis and treatment of acute and chronic heart failure 2008: the task force for the diagnosis and treatment of acute and chronic heart failure 2008 of the European Society of Cardiology. Developed in collaboration with the Heart Failure Association of the ESC (HFA) and endorsed by the European Society of Intensive Care Medicine (ESICM). Eur Heart J. 2008;29:2388-442.

12. Fallick C, Sobotka PA, Dunlap ME. Sympathetically mediated changes in capacitance: redistribution of the venous reservoir as a cause of decompensation. Circ Heart Fail. 2011;4:669-75.

13. Fudim M, Hernandez AF, Felker M. Role of volume redistribution in the congestive heart failure. J Am Heart Assoc. 2017;6:e006817.

14. Martens P, Mullens W. How to tackle congestion in acute heart failure. Korean J Intern Med. 2018;33: 462-73.

15. Gheorghiade M, Pang PS. Acute heart failure syndromes. J Am Coll Cardiol. 2009;53:557-73.

16. Mullens W, Verbrugge FH, Nijst P, Tang WHW. Renal sodium avidity in heart failure: from pathophysiology to treatment strategies. Eur Heart J. 2017;38:1872-82. 
17. Ellison DH, Felker GM. Diuretic treatment in heart failure. N Engl J Med. 2017;377:1964-75.

18. Mullens W, Damman K, Harjola VP, et al. The use of diuretics in heart failure with congestion: a position statement from the Heart Failure Association of the European Society of Cardiology. Eur J Heart Fail. 2019;21:137-55.

19. Grodin JL, Simon J, Hachamovitch R, et al. Prognostic role of serum chloride levels in acute decompensated heart failure. J Am Coll Cardiol. 2015;66:659-66.

20. Hanberg JS, Rao V, ter Maaten JM, et al. Hypochloremia and diuretic resistance in heart failure: mechanistic insights. Circ Heart Fail. 2016;9: e003180.

21. Kataoka H. The, "chloride theory", a unifying hypothesis for renal handling and body fluid distribution in heart failure pathophysiology. Med Hypotheses. 2017;104:170-3.

22. Schrier RW, Abraham WT. Hormones and hemodynamics in heart failure. N Engl J Med. 1999;341: 577-85.

23. Schrier RW. Decreased effective blood volume in edematous disorders: what does this mean? J Am Soc Nephrol. 2007;18:2028-31.

24. Cody RJ, Covit AB, Schaer GL, Laragh JH, Sealey JE, Feldschuh J. Sodium and water balance in chronic congestive heart failure. J Clin Investig. 1986;77: 1441-52.

25. Volpe M, Tritto C, DeLuca N, et al. Abnormalities of sodium handling and of cardiovascular adaptations during high salt diet in patients with mild heart failure. Circulation. 1993;88(part 1):1620-7.

26. Sica DA. Sodium and water retention in heart failure and diuretic therapy: basic mechanisms. Clevel Clin J Med. 2006;73(suppl 2):S2-7.

27. Kataoka H. Vascular expansion during worsening of heart failure: effects on clinical features and its determinants. Int J Cardiol. 2017;230:556-61.

28. Kataoka H. Proposal for heart failure progression based on the "chloride theory": worsening heart failure with increased vs. non-increased serum chloride concentration. ESC Heart Fail. 2017;4: 623-31.

29. Kataoka H. Biochemical determinants of changes in plasma volume after decongestion therapy for worsening heart failure. J Card Fail. 2019;25:213-7.

30. Kataoka H. Changes in red blood cell volume during transition of heart failure status: a reflection of cellular hydration status? Scand J Clin Lab Investig. 2018;78:305-11.

31. Kataoka H. Treatment of hypochloremia with acetazolamide in an advanced heart failure patient and importance of monitoring urinary electrolytes. J Cardiol Cases. 2018;17:80-4.

32. Edelman IS, Leibman J. Anatomy of body water and electrolytes. Am J Med. 1959;27:256-77.

33. Bhave G, Neilson EG. Body fluid dynamics: back to the future. J Am Soc Nephrol. 2011;22:2166-81.

34. Nijst P, Verbrugge FH, Grieten L, et al. The pathophysiological role of interstitial sodium in heart failure. J Am Coll Cardiol. 2015;65:378-88.

35. Wiig H. Regulation of fluid volume from the outside: a role of glycosaminoglycans in the skin interstitium? Circ Heart Fail. 2018;11:e005135.

36. Michel CC. Starling: the formulation of his hypothesis of microvascular fluid exchange and its significance after 100 years. Exp Physiol. 1997;82: $1-30$.

37. Prowle JR, Echeverri JE, Liǵabo EV, Ronco C, Bellomo R. Fluid balance and acute kidney injury. Nat Rev Nephrol. 2010;6:107-15.

38. Harjola VP, Mullens W, Banaszewski M, et al. Organ dysfunction, injury and failure in acute heart failure: from pathophysiology to diagnosis and management: a review on behalf of the Acute Heart Failure Committee of the Heart Failure Association (HFA) of the European Society of Cardiology (ESC). Eur J Heart Fail. 2017;19:821-36.

39. Miller WL, Mullan BP. Understanding the heterogeneity in volume overload and fluid distribution in decompensated heart failure is key to optimal volume management: role for blood volume quantitation. J Am Coll Cardiol Heart Fail. 2014;2: 298-305.

40. Miller WL, Mullan BP. Volume overload profiles in patients with preserved and reduced ejection fraction chronic heart failure: are there differences? J Am Coll Cardiol Heart Fail. 2016;4:453-9.

41. Miller WL. Fluid volume overload and congestion in heart failure: time to reconsider pathophysiology and how volume is assessed. Circ Heart Fail. 2016;9: e002922.

42. Katz SD. In search of euvolemia in heart failure. J Am Coll Cardiol Heart Fail. 2014;2:306-7.

43. Grodin JL. Pharmacologic approaches to electrolyte abnormalities in heart failure. Curr Heart Fail Rep. 2016;13:181-9. 
44. Verbrugge FH, Steels P, Grieten L, Nijst P, Tang WH, Mullens W. Hyponatremia in acute decompensated heart failure: depletion versus dilution. J Am Coll Cardiol. 2015;65:480-92.

45. Kataoka H. Dynamic changes in serum chloride concentrations during worsening of heart failure and its recovery following conventional diuretic therapy: a single center study. Health Sci Rep. 2018;1:e94.

46. Jentzer JC, DeWald TA, Hernandez AF. Combination of loop diuretics with thiazide-type diuretics in heart failure. J Am Coll Cardiol. 2010;56:1527-34.

47. ter Maaten JM, Valente MAE, Damman K, Hillege HL, Navis G, Voors AA. Diuretic response in acute heart failure: pathophysiology, evaluation, and therapy. Nat Rev Cardiol. 2015;12:184-92.

48. Tahara A, Kurosaki E, Yokono M, et al. Pharmacological profile of ipragliflozin (ASP1941), a novel selective SGLT2 inhibitor, in vitro and in vivo. Naunyn Schmiedeberg Arch Pharmacol. 2012;385: 423-36.

49. Costello-Boerrigter LC, Smith WB, Boerrigter G, et al. Vasopressin-2-receptor antagonism augments water excretion without changes in renal hemodynamics or sodium and potassium excretion in human heart failure. Am J Physiol Renal Physiol. 2006;290:F273-F278.

50. Kataoka H, Yamasaki Y. Strategy for monitoring decompensated heart failure treated by an oral vasopressin antagonist with special reference to the role of serum chloride: a case report. J Card Cases. 2016;14:185-8.

51. Tamaki S, Sato Y, Yamada T, et al. Tolvaptan reduces the risk of worsening renal function in patients with acute decompensated heart failure and preserved left ventricular ejection fraction: prospective randomized controlled study. Circ J. 2017;81:740-7.

52. Elkinton JR, Squires RD, Bluemle LW Jr. The distribution of body fluids in congestive heart failure. IV. Exchanges in patients, refractory to mercurial diuretics, treated with sodium and potassium. Circulation. 1952;5:58-73.

53. Hirotani S, Masuyama T. When to increase or reduce sodium loading in the management of fluid volume status during acute decompensated heart failure. ESC Heart Fail. 2014;1:75-81.

54. Kataoka H. Comparison of changes in plasma volume and renal function between acetazolamide and conventional diuretics: understanding the mechanical differences according to the "chloride theory". Cardiology. 2020;145:215-23.
55. Khan MI. Treatment of refractory congestive heart failure and normokalemic hypochloremic alkalosis with acetazolamide and spironolactone. Can Med Assoc J. 1980;123:883-7.

56. Caramelo C, Albalate M, Alcázar TR, Baldoví S, Pérez AG, Marín M. Actuality of the use of acetazolamide as a diuretic: usefulness in refractory edema and in aldosterone-antagonist-related hyperkalemia. Nefrologia. 2008;28:234-8.

57. Imiela T, Budaj A. Acetazolamide as add-on diuretic therapy in exacerbations of chronic heart failure: a pilot study. Clin Drug Investig. 2017;37:1175-81.

58. Kataoka H. Vasopressin antagonist-like effect of acetazolamide in a heart failure patient: a case report. Eur Heart J Case Rep. 2018;2:1-5.

59. Kataoka H. Acetazolamide as a potent chloride-regaining diuretic: short- and long-term effects, and its pharmacologic role under the 'chloride theory' for heart failure pathophysiology. Heart Vessels. 2019;34:1952-60.

60. Lambers Heerspink HJ, de Zeeuw D, Wie L, Leslie B, List J. Dapagliflozin a glucose-regulating drug with diuretic properties in subjects with type 2 diabetes. Diabetes Obes Metab. 2013;15:853-62.

61. Vallon V, Thomson SC. Targeting renal glucose reabsorption to treat hyperglycaemia: the pleiotropic effects of SGLT2 inhibition. Diabetologia. 2017;60:215-25.

62. McMurray JJ, Solomon SD, Inzucchi SE, et al. Dapagliflozin in patients with heart failure and reduced ejection fraction. N Engl J Med. 2019;381: 1995-2008.

63. Chen L, LaRocque L, Efe O, Wang J, Sands JM, Klein JD. Effect of dapagliflozin treatment on fluid and electrolyte balance in diabetic rats. Am J Med Sci. 2016;352:517-23.

64. Masuda T, Watanabe Y, Fukuda K, et al. Unmasking a sustained negative effect of SGLT2 inhibition on body fluid volume in the rat. Am J Physiol Renal Physiol. 2018;315:F653-F664.

65. Kataoka H, Yoshida Y. Enhancement of the serum chloride concentration by administration of sodium-glucose transporter-2 inhibitor and its mechanisms and clinical significance in type 2 diabetic patients: a pilot study. Diabetol Metab Syndr. 2020;12:5.

66. Hallow K, Helmlinger G, Greasly PJ, McMurray JJ, Boulton DW. Why do SGLT2 inhibitors reduce heart failure hospitalization? A differential volume regulation hypothesis. Diabetes Obes Metab. 2018;20:479-87. 
67. Mullens W, Abrahams Z, Skouri HN, et al. Elevated intra-abdominal pressure in acute decompensated heart failure: a potential contributor to worsening renal function? J Am Coll Cardiol. 2008;51:300-6.

68. Mullens W, Abrahams Z, Francis GS, et al. Importance of venous congestion for worsening of renal function in advanced decompensated heart failure. J Am Coll Cardiol. 2009;53:589-96.

69. Cops J, Haesen S, de Moor B, Mullens W, Hansen D. Current animal models for the study of congestion in heart failure: an overview. Heart Fail Rev. 2019;24:387-97.

70. Testani JM, Chen J, McCauley BD, Kimmel SE, Shannon RP. Potential effects of aggressive decongestion during the treatment of decompensated heart failure on renal function and survival. Circulation. 2010;122:265-72.

71. Testani JM, Brisco MA, Chen J, McCauley BD, Parikh CR, Tang WH. Timing of hemoconcentration during treatment of acute decompensated heart failure and subsequent survival: importance of sustained decongestion. J Am Coll Cardiol. 2013;62: 516-24.

72. Breidthardt T, Weidmann ZM, Twerenbold R, et al. Impact of haemoconcentration during acute heart failure therapy on mortality and its relationship with worsening renal function. Eur J Heart Fail. 2017;19:226-36.

73. Darawsha W, Chirmicci S, Solomonica A, et al. Discordance between hemoconcentration and clinical assessment of decongestion in acute heart failure. J Card Fail. 2016;22:680-8.

74. Lucas C, Johnson W, Hamilton MA, et al. Freedom from congestion predicts good survival despite previous class IV symptoms of heart failure. Am Heart J. 2000;140:840-7.

75. Metra M, Davison B, Bettari L, et al. Is worsening renal function an ominous prognostic sign in patients with acute heart failure? The role of congestion and its interaction with renal function. Circ Heart Fail. 2012;5:54-62.

76. Nassif M, Windsor SL, Tang F, et al. Dapagliflozin effects on biomarkers, symptoms, and functional status in patients with heart failure with reduced ejection fraction: the DEFINE-HF trial. Circulation. 2019;140:1463-76.

77. Damman K, Beusekamp JC, Boorsma EM, et al. Randomized, double-blind, placebo-controlled, multicenter pilot study on the effects of empagliflozin on clinical outcomes in patients with acute decompensated heart failure (EMPA-RESPONSE-
AHF). Eur J Heart Fail. 2020. https://doi.org/10. 1002/ejhf.1713.

78. Goldsmith SR, Gheorghiade M. Vasopressin antagonism in heart failure. J Am Coll Cardiol. 2005;46: 1785-91.

79. Udelson JE, Orlandi C, Ouyang J, et al. Acute hemodynamic effects of tolvaptan, a vasopressin $\mathrm{V}_{2}$ receptor blocker, in patients with symptomatic heart failure and systolic dysfunction: an international, multicenter, randomized, placebo-controlled trial. J Am Coll Cardiol. 2008;52:1540-5.

80. von Lueder TG, Atar D, Krum H. Diuretic use in heart failure and outcomes. Clin Pharmacol Ther. 2013;94:490-8.

81. Valente MAE, Voors AA, Damman K, et al. Diuretic response in acute heart failure: clinical characteristics and prognostic significance. Eur Heart J. 2014;35:1284-93.

82. Voors AA, Davison BA, Teerlink JR, et al. Diuretic response in patients with acute decompensated heart failure: characteristics and clinical outcomean analysis from RELAX-AHF. Eur J Heart Fail. $2014 ; 16: 1230-40$.

83. Ellison DH. The physiologic basis of diuretic synergism: its role in treating diuretic resistance. Ann Intern Med. 1991;114:886-94.

84. Verbrugge FH. Diuretic resistance in acute heart failure. Eur Heart J Acute Card Care. 2018;7:379-89.

85. Dzau VJ, Colucci WS, Hollenberg NK, Williams GH. Relation of the renin-angiotensin-aldosterone system to clinical state in congestive heart failure. Circulation. 1981;63:645-51.

86. Lilly LS, Dzau VJ, Williams GH, Rydstedt L, Hollenberg NK. Hyponatremia in congestive heart failure: implications for neurohumoral activation and responses to orthostasis. J Clin Endocrinol Metab. 1984;59:924-30.

87. Packer M, Medina N, Yushak M. Relation between serum sodium concentration and the hemodynamic and clinical responses to converting enzyme inhibition with captopril in severe heart failure. J Am Coll Cardiol. 1984;3:1035-43.

88. Ghali JK, Tam SW. The critical link of hypervolemia and hyponatremia in heart failure and the potential role of arginine vasopressin antagonists. J Card Fail. 2010;16:419-31.

89. Crespo-Leiro MG, Metra M, Lund LH, et al. Advanced heart failure: a position statement of Heart Failure Association of the European Society of Cardiology. Eur J Heart Fail. 2018;20:1505-35. 
90. Kelder JC, Cramer MJ, van Wijngaarden J, et al. The diagnostic value of physical examination and additional testing in primary care patients with suspected heart failure. Circulation. 2011;124: 2865-73.

91. Kataoka H. Detection of preclinical body fluid retention in established heart failure patients during follow-up by a digital weight scale incorporating a bioelectrical impedance analyzer. Congest Heart Fail. 2012;18:37-42.

92. Kataoka H. Ultrasound pleural effusion sign as a useful marker for identifying heart failure worsening in established heart failure patients during follow-up. Congest Heart Fail. 2012;18:272-7.

93. Cowie MR, Anker SD, Cleland JG, et al. Improving care for patients with acute heart failure: before, during and after hospitalization. ESC Heart Fail. 2014;1:110-45.

94. Kataoka H. Clinical significance of bilateral leg edema and added value of monitoring weight gain during follow-up of patients with established heart failure. ESC Heart Fail. 2015;2:106-15.

95. The Task Force for the diagnosis and treatment of acute and chronic heart failure of the European Society of Cardiology (ESC). 2016 ESC Guidelines for the diagnosis and treatment of acute and chronic heart failure. Eur J Heart Fail. 2016;18: 891-975.

96. Thibodeau JT, Drazner MH. The role of the clinical examination in patients with heart failure. J Am Coll Cardiol Heart Fail. 2018;6:543-51.

97. Girerd N, Seronde M-F, Coiro S, et al. Integrative assessment of congestion in heart failure throughout the patient journey. J Am Coll Cardiol Heart Fail. 2018;6:273-85.

98. Harjola VP, Parissis J, Brunner-La Rocca HP, et al. Comprehensive in-hospital monitoring in acute heart failure: applications for clinical practice and future directions for research. A statement from Acute Heart Failure Committee of the Heart Failure Association (HFA) of the European Society of Cardiology (ESC). Eur J Heart Fail. 2018;20:1081-99.

99. Piano MR, Prasun MA, Stamos T, Groo V. Flexible diuretic titration in chronic heart failure: where is the evidence? J Card Fail. 2011;17:944-54.

100. Evangelista LS, Dracup K, Doering LV. Treatmentseeking delays in heart failure patients. J Heart Lung Transplant. 2000;19:932-8.

101. Schiff GD, Fung S, Speroff T, McNutt RA. Decompensated heart failure: symptoms, patterns of onset, and contributing factors. Am J Med. 2003;114: 625-30.

102. Lien CT, Gillespie ND, Struthers AD, McMurdo ME. Heart failure in frail elderly patients: diagnostic difficulties, co-morbidities, polypharmacy and treatment dilemmas. Eur J Heart Fail. 2002;4:91-8.

103. van Riet EES, Hoes AW, Limburg A, Landman MAJ, van der Hoeven $H$, Rutten FH. Prevalence of unrecognized heart failure in older persons with shortness of breath on exertion. Eur J Heart Fail. 2014;16:772-7.

104. Breidthardt T, Moreno-Weidmann Z, Uthoff $H$, et al. How accurate is clinical assessment of neck veins in the estimation of central venous pressure in acute heart failure?: insights from a prospective study. Eur J Heart Fail. 2018;20:1160-2.

105. Kataoka H, Matsuno O. Age-related pulmonary crackles (rales) in asymptomatic cardiovascular patients. Ann Fam Med. 2008;6:239-45.

106. Kataoka H. Clinical characteristics of lower-extremity edema in stage A cardiovascular disease status defined by ACC/AHA 2001 chronic heart failure guidelines. Clin Cardiol. 2013;36:555-9.

107. Dhaliwal AS, Deswal A, Pritchett A, et al. Reduction in BNP levels with treatment of decompensated heart failure and future clinical events. J Card Fail. 2009;15:293-9.

108. McDonald K, Troughton R, Dahlström U, et al. Daily home BNP monitoring in heart failure for prediction of impending clinical deterioration: results from the HOME HF study. Eur J Heart Fail. 2018;20:474-80.

109. Kataoka H. Relation of body fluid status to b-type natriuretic peptide levels in patients with chronic heart failure during long-term follow-up. Clin Cardiol. 2006;29:457-61.

110. Täger T, Wiedergruen A-K, Fröhlich H, et al. Hemodynamic determinants of the biologic variation of N-terminal pro-B-type natriuretic peptide in patients with stable systolic chronic heart failure. J Card Fail. 2017;23:835-42.

111. Kataoka H. A new monitoring method for the estimation of body fluid status by digital weight scale incorporating bioelectrical impedance analyzer in definite heart failure patients. J Card Fail. 2009;15: 410-8.

112. Cheuvront SN, Ely BR, Kenefick RW, Sawka MN. Biological variation and diagnostic accuracy of dehydration assessment markers. Am J Clin Nutr. 2010;92:565-73. 
113. Collins SP, Lindsell CJ, Storrow AB, ADHERE Scientific Advisory Committee, Investigators, and Study Group. Prevalence of negative chest radiography results in the emergency department patient with decompensated heart failure. Ann Emerg Med. 2006;47:13-8.

114. Platz E, Merz AA, Jhund PS, Vazir A, Campbell R, McMurray JJ. Dynamic changes and prognostic value of pulmonary congestion by lung ultrasound in acute and chronic heart failure: a systemic review. Eur J Heart Fail. 2017;19:1154-63.

115. Kataoka H, Takada S. The role of thoracic ultrasonography for evaluation of patients with decompensated chronic heart failure. J Am Coll Cardiol. 2000;35:1638-46.

116. Kataoka H. Practical use of acetazolamide for heart failure patients according to the "chloride theory": literature review and case vignettes. In: Bennington $\mathrm{EH}$, editor. Horizons in world cardiovascular. 18th ed. New York: Nova Science; 2020. p. 69-92.

117. Felker GM, Lee KL, Bull DA, et al. Diuretic strategies in patients with acute decompensated heart failure. N Engl J Med. 2011;364:797-805.

118. Damman K, Ter Maaten JM, Coster JE, et al. Clinical importance of urinary sodium excretion in acute heart failure. Eur J Heart Fail. 2020. https://doi.org/ 10.1002/ejhf.1753.

119. Mentz RJ, Stevens SR, DeVore AD, et al. Decongestion strategies and renin-angiotensin-aldosterone system activation in acute heart failure. J Am Coll Cardiol Heart Fail. 2015;3:97-107.

120. Kataoka H. Rational of the "chloride theory" as an explanation for neurohormonal activity in heart failure pathophysiology: literature review. J Clin Exp Cardiol. 2019;10:634.

121. Schwartzenberg S, Redfield MM, From AM, Sorajja P, Nishimura RA, Borlaug BA. Effects of vasodilation in heart failure with preserved or reduced ejection fraction: implications of distinct pathophysiologies on response to therapy. J Am Coll Cardiol. 2012;59: 442-51.

122. Asada K, Fujiu K, Imai Y, et al. Intrathoracic impedance monitoring in patients with heart failure: correlation with dehydration and bleeding events. Circ J. 2012;76:2592-8.

123. Miller WL, Borlaug B. Impact of obesity on volume status in patients with ambulatory chronic heart failure. J Card Fail. 2020;26:112-7.

124. Reddy YN, Obokata M, Testani JM, et al. Adverse renal response to decongestion in the obese phenotype of heart failure with preserved ejection fraction. J Card Fail. 2020;26:101-7.

125. Komajda M, Lam CS. Heart failure with preserved ejection fraction: a clinical dilemma. Eur Heart J. 2014;35:1022-32.

126. Shah SJ, Kitzman DW, Borlaug BA, et al. Phenotypespecific treatment of heart failure with preserved ejection fraction: a multiorgan roadmap. Circulation. 2016;134:73-90.

127. Van Aelst LN, Arrigo M, Placido R, et al. Acutely decompensated heart failure with preserved and reduced ejection fraction present with comparable haemodynamic congestion. Eur J Heart Fail. 2018;20:738-47. 